\title{
Patient Participation in Nursing Care on Medical Wards: An Integrative Review
}

\section{Title Page}

Name: Georgia Tobiano

Job title: PhD Candidate

Highest academic and professional qualification: BN (Hons), RN

Institution (and corresponding author's address): Centre for Health Practice Innovation, Menzies Health Institute Queensland, Griffith University, Gold Coast Campus, Parklands Drive, Queensland, 4222, Australia

Address for corresponding author:

Phone number for corresponding author: +61402 869972

Email for corresponding author: g.tobiano@griffith.edu.au

Name: Andrea Marshall

Job title: Professor of Acute and Complex Care Nursing ${ }^{\text {ab }}$

Highest academic and professional qualification: $\mathrm{PhD}, \mathrm{RN}$

Institution: National Centre of Research Excellence in Nursing Interventions for Hospitalised Patients, Centre for Health Practice Innovation, Menzies Health Institute Queensland, Griffith University, Queensland, Australia ${ }^{\mathrm{a}}$ and Gold Coast Health, Queensland, Australia ${ }^{\mathrm{b}}$

Name: Tracey Bucknall

Job title: Professor ${ }^{\mathrm{a}}$ and Foundational Chair in Nursing ${ }^{\mathrm{b}}$

Highest academic and professional qualification: $\mathrm{PhD}, \mathrm{RN}$

Institution: Centre for Quality and Patient Safety, School of Nursing and Midwifery, Deakin University, Victoria, Australia ${ }^{a}$ and Alfred Health, Victoria, Australia ${ }^{b}$

Name: Wendy Chaboyer

Job title: Professor and Director

Highest academic and professional qualification: $\mathrm{PhD}, \mathrm{RN}$

Institution: National Centre of Research Excellence in Nursing Interventions for Hospitalised

Patients, Centre for Health Practice Innovation, Menzies Health Institute Queensland, Griffith University, Queensland, Australia 


\title{
Patient Participation in Nursing Care on Medical Wards: An Integrative Review
}

\begin{abstract}

\section{Background}

Patient participation is a way for patients to engage in their nursing care. In view of the possible link between patient participation and safety, there is a need for an updated review to assess patient participation in nursing care.
\end{abstract}

\section{Objectives}

To investigate patients’ and nurses’ perceptions of and behaviours towards patient participation in nursing care in the context of hospital medical wards.

\section{Design}

Integrative review.

\section{Data sources}

Three search strategies were employed in August 2013; a computerised database search of Cumulative Index of Nursing and Allied Health Literature, Cochrane Library, Medline and PsychINFO; reference lists were hand-searched; and forward citation searching was executed.

\section{Review methods}

After reviewing the studies, extracting study data and completing summary tables the methodological quality was assessed using the Mixed-Methods Assessment Tool by two reviewers. Reviewers met then to discuss discrepancies as well as the overall strengths and limitations of the studies. Discrepancies were overcome through consensus or a third reviewer adjudicated the issue. Within and across study analysis and synthesis of the findings sections was undertaken using thematic synthesis. 


\section{Results}

Eight studies met inclusion criteria. Four themes were identified - enacting participation, challenges to participation, promoting participation and types of participation. Most studies included were conducted in Europe. The majority of studies used qualitative methodologies, with all studies sampling patients; nurses were included in three studies. Data were largely collected using self-reported perceptions; two studies included observational data. Methodological issues included a lack of reflexivity, un-validated data collection tools, sampling issues and low response rates.

\section{Conclusions}

On medical wards, patients and nurses desire, perceive or enact patient participation passively. Challenging factors for patient participation include patients' willingness, nurses' approach and confusion around expectations and roles. Information sharing was identified as an activity that promotes patient participation, suggesting nurses encourage active communication with patients in practice. Involving patients in assessment and care planning may also enhance patient participation. For education, enhancing nurses understanding of the attributes of patient participation, as well as patient-centred care approaches may be beneficial for medical ward nurses. From here, researchers need to examine ways to overcome the barriers to patient participation; further nurse participants and observational data is required on medical wards.

\section{Key words}

Communication; consumer participation; cooperative behaviour; nurse-patient relations; patient-centered care; patient engagement; patient involvement; patient participation; shared decision-making; review. 


\section{Patient Participation in Nursing Care on Medical Wards: An Integrative Review}

\section{Introduction}

Hospitals may not be the safest place with approximately 1 in 10 patients experiencing an adverse event (de Vries et al., 2008). In 2014, a Canadian study found 1 in 7 patients hospitalised on medical wards had an adverse event (D'Amour et al., 2014). Internationally, patient-centred care is advocated as an approach to reduce adverse events in hospitals (Australian Comission on Safety and Quality in Health Care (ACSQHC), 2011), with governing bodies such as the National Institute for Health and Care Excellence (NICE) (2012), American Hospital Association (AHA) (2014) and ACSQHC (2014) developing resources to enhance practices of patient-centred care in hospitals. Patient participation is a key concept of patient-centred care (Kitson et al., 2013) and has been suggested as a way for patients to ensure safety, owing to their prominence in their own care (Koutantji et al., 2005).

\section{Background}

Patient participation is a diverse term encompassing a large range of activities. The various terminology used synonymously with participation included engagement, involvement (Gallivan et al., 2012), collaboration, and cooperation while patients are described as clients, consumers and users (Langton et al., 2003). The activity 'decisionmaking' has been promoted as a way for patients to be involved in healthcare, which reflects patients’ rights (Entwistle, 2000). However, nursing activities that patients may engage in are diverse, including handover (Chaboyer et al., 2008), medication rounds (Bolster and Manias, 2010), nursing care planning (Kolovos et al., 2014) and managing own care (Sørensen et al., 2013). 
The definition of patient participation lacks consensus (Longtin et al., 2010). Recent definitions of patient participation highlight nurses’ requirement to enact patient-centred qualities such as respect and empowerment, and to involve patients in all elements of their care (University of Gothenburg Centre for Person-centred Care (GPCC), 2014). For example, Sahlsten et al.'s (2008) concept analysis provides insights into the phenomenon of patient participation. Although the concepts are tentative, Sahlsten et al.’s (2008) analysis incorporates various researchers' attempts to provide clarity around 'patient participation'. With features of the concept recognisable in recent research (Eldh et al., 2010, Soleimani et al., 2010), this definition seems appropriate and this review may contribute to maturity of the concept. According to Sahlsten et al (2008), patient participation in nursing care is characterised by four defining attributes including a strong existing nurse-patient relationship, relinquishing of power by nurses, mutual exchange of information and knowledge between patient and nurse, and collaboration in intellectual and/or physical activities; this latter attribute being dependent on the presence of the first three.

Research to date shows apparent benefits for patients who participate in their care. Patient participation in enhancing safety practices in hospital is a convincing concept (Coulter and Ellins, 2007, Longtin et al., 2010), especially when patients self-manage medications (Hall et al., 2010). One recent US study found the risk of experiencing an adverse event was half as likely, when patient participation was implemented (Weingart et al., 2011). However further evidence of the effectiveness of patient participation in safety activities is required (Berger et al., 2013, Schwappach, 2010).

Patient participation also benefits the patient in other ways including enhancing patient knowledge (Coulter and Ellins, 2007) and sense of control (Dudas et al., 2013, Höglund et al., 2010). Patient-centred approaches, inclusive of patient participation, also improve patient satisfaction (Dwamena et al., 2012) and perceived quality of care (Slatore, 
2010, Weingart et al., 2011). Finally, involving patients in their care can improve condition (Coulter and Ellins, 2007), specifically patients' function in activities of daily living (Ekman et al., 2012). The potential positive outcomes of patient participation suggest encouraging patient participation in nursing care, may benefit the patient.

\section{Previous reviews}

There are several reviews on patient participation in care, with a particular focus on patient safety (Berger et al., 2013, Hall et al., 2010, Peat et al., 2010). A recent review by Vaismoradi et al. (2014) examined patient participation in safety in nursing care, however, only one review has explicitly investigated patient participation in general nursing care (Cahill, 1998). Cahill’s (1998) review was conducted over 15 years ago and it is likely that approaches to patient participation have evolved since this time, particularly in relation to the strong recent focus on patient safety. In this early review (Cahill, 1998), the researcher’s attempt to understand patient participation in nursing care was hindered by a lack of available research, consequently studies relating to doctors/medical care were also included. Overall, the review by Cahill (1998) was inconclusive and the need for further research to evaluate patients' and nurses' perspectives and behaviours towards patient participation, especially utilising qualitative or mixed method approaches, was identified. In light of previous reviews, the aim of this integrative review was to investigate patients' and nurses' perceptions of, and behaviours towards, patient participation in nursing care.

\section{Methods}

An integrative review was conducted as it allowed qualitative and quantitative methodologies to be synthesized; ensuring a variety of sources of patients' and nurses' perspectives and behaviours were included. This review was guided by Whittemore and Knafl's (2005) integrative review framework to enhance rigor. 


\section{Sample and inclusion/exclusion criteria}

Inclusion/exclusion criteria were based on the concepts studied, target population, health care problem and sampling frame (Whittemore and Knafl, 2005). Included studies had to meet the following inclusion criteria. First, the sample had to include either adult patients or nurses in medical units of hospitals. Because medical patients tend to have multiple comorbidities and chronic conditions, a focus on this group was to capture patients who have more opportunity to participate in nursing care because of their 'exposure'. Additionally, it is likely that other patient populations, such as surgical, mental health or rehabilitation patients would have different experiences, making pooling of findings from these disparate populations less meaningful and not applicable to the clinical context. Second, studies also had to have an explicit focus on participation in either intellectual or physical activities and include either perceptions or actual behaviours. Only the fourth attribute, mutual engagement in physical and/or intellectual activities, was included as its success hinges on the remaining attributes. Further, this attribute identifies kinds of perceived and enacted participation that can occur. Finally, only empirical, full-text studies, published in English were included. Studies published between 1999-2013 were included to capture those published after Cahill's (1998) review. Studies that included areas other than medical wards, or other health professional in addition to nurses, were subsequently excluded if they did not report findings for the subsample of medical patients and/or nurses.

\section{Literature search}

In August 2013, three search strategies were employed to enhance the quality of this review (Whittemore and Knafl, 2005), with search strategy one informing search two and three. With the assistance of a health librarian, a computerised database search of the Cumulative Index of Nursing and Allied Health Literature (CINAHL), Cochrane Library, 
Medline and PsycINFO was performed due to their comprehensiveness and appropriateness for the topic. The first strategy was guided by three elements of the SPIDER tool; phenomenon of interest, sample and evaluation. This tool assists in creating sound search strategies, particularly when anticipating retrieval of qualitative and mixed-methods studies (Cooke et al., 2012). Step 1 focused on the phenomenon of interest, terms used synonymously for patient participation were searched (Table 1). The sample was identified in step 2 and 4, being hospitalised, adult patients and nurses. In step 2 methods of evaluation, including perceptions and behaviours, were linked to medical subject heading (MeSH) terms. Consistent with integrative review there were no restrictions on research designs or study types. To meet inclusion criteria, restrictions were placed on language and years published. The second search strategy involved hand-searching reference lists of retrieved articles to find relevant literature not previously identified. Third, the citations of retrieved articles were searched using Scopus to identify subsequent articles.

Table 1 here

\section{Search outcome}

The combined search strategies resulted in eight articles meeting the inclusion criteria (Figure 1). One author undertook the search, and two researchers determined the eligibility of studies for inclusion.

Figure 1 here

\section{Data extraction and evaluation}

To provide an overview, data were extracted relating to approach, context, sample and key findings. Quality scores were calculated using the Mixed Methods Assessment Tool (MMAT) (Table 2). The MMAT was used to concurrently evaluate the quality of various methodologies and has established validity and reliability (Pace et al., 2010, Pace et al., 2012, 
Pluye et al., 2009). Studies were assessed against the appropriate MMAT criteria based on the methodology used, and were assigned quality scores ranging from (*) representing one criteria met through to $(* * * *)$ representing all criteria (Pluye et al., 2011). Two researchers independently appraised each article and then discussed their MMAT scores and the overall strengths and limitations of the study. All researchers participated in the review process. Discrepancies were resolved through discussion and reference to the MMAT tutorial (Pluye et al., 2011). A third reviewer was available to adjudicate however this was not required. Quality scores were not used to exclude studies as all studies met at least two criteria, but instead highlighted the potential contribution of each study to the overall findings.

\section{Data analysis}

Thematic synthesis was used for analysing and synthesising the findings of the included studies, using Thomas and Harden’s (2008) work as a guide. First, the researcher became immersed in the data by reading and re-reading the sections labelled "results" or "findings" of each article, maintaining notes of possible patterns and decisions throughout the thematic analysis and synthesis. Second, the findings or results sections were analysed inductively. Line by line coding using words was undertaken, with analysis occurring within and across studies. NVivo 10 software (QSR International) was used to assist with data management. Next, inductive codes were grouped into hierarchies of categories and subcategories, producing largely descriptive categories. Finally, the categories were searched for the latent themes that went beyond the original content of the studies to provide a metasynthesis.

Findings were also coded deductively, using Soleimani et al.’s (2010) core category “convergence of caring agents” as a framework to uncover the types of participation reported. This core category included four subcategories, which represented levels of participation: 
adhering, involving, sharing and true participation (Soleimani et al., 2010). Each study was assessed against the four subcategories to find which level of participation was achieved. The subcategory adhering, portrayed patient passivity, whereby patients trusted nurses and followed their instructions with little engagement (Soleimani et al., 2010). When patients adhered, nurses were in control, displaying task-orientated behaviour and not encouraging patient interaction (Soleimani et al., 2010). The next subcategory, involving, was characterised by information-seeking behaviours by patients, which was encouraged by nurses (Soleimani et al., 2010). The subcategory entitled sharing, was described as patients contributing to physical cares and nurses promoting patients to take on this responsibility, within nursing legislation (Soleimani et al., 2010). Patients and nurses were both eager to participate when the final subcategory, true participation, was achieved. True participation included patients undertaking self-care, managing their care, sharing their views and making decisions (Soleimani et al., 2010). At this level of participation, nurses valued the illness knowledge that patients shared (Soleimani et al., 2010).

\section{Findings}

A summary of the eight studies meeting the inclusion criteria for the integrative review are presented in Table 2. Despite three studies employing quantitative methodologies, the findings produced were easily understood in a descriptive manner and results and graphs were transformed into words and descriptions (Sandelowski et al., 2006). This enabled comparison of the quantitative and qualitative findings (Sandelowski et al., 2006, Voils et al., 2008), with both complementing each other and contributing to a rich description of patient participation in the medical context.

Table 2 here. 
The research context can be seen in Table 2, with six of the eight studies being conducted in European hospitals, predominately in Sweden; the remaining two studies were undertaken in Australia and Iran. Attempts to enhance credibility through investigating different settings were noted with most researchers studying more than one medical ward. Contextual descriptions tended to be generic, explaining countries position towards patient participation rather than thick contextual descriptions about the ward and hospital that related that patient participation.

In terms of sample (Table 2), all studies explored patients’ perceptions of patient participation; only three studies included nurses as study participants (Florin et al., 2006, Lomborg and Kirkevold, 2008, Soleimani et al., 2010). The patient population across the studies had an average age ranging from 50-68 years and a variety of medical conditions. The average age of nurses ranged from 31-34 years and the average experience varied considerably, ranging from 1.5 years to 10 years. Transferability was addressed with five of the eight studies identifying types of medical conditions of patient participants. Only three research teams (Florin et al., 2008, Florin et al., 2006, Lomborg and Kirkevold, 2008) explicitly reported wellness of the patient, which may be important for patient participation.

The methodological quality of qualitative studies ranged from moderate $(* *)$ to high $(* * * *)$ (Table 2). The most common critique of qualitative pieces was the researchers not addressing their influence on data collection, seemingly important as these researchers had nursing qualifications. Two of the research teams undertook observations; however, the researchers failed to explicitly detail strategies for acknowledging their assumptions (Lomborg and Kirkevold, 2008, Soleimani et al., 2010), whereby methods of self-reflection would have enhanced rigor during data collection (Polit and Beck, 2008). A further example was Doherty and Doherty’s (2005) interpretive phenomenology, with the methodology encompassing identification of pre-understandings, which was not addressed. 
Shown in Table 2, the methodological quality of quantitative pieces was moderate $(* *)$ due to data collection tools, sampling and response rates. In the studies reviewed data collection tools were modified and not validated (Florin et al., 2008, Florin et al., 2006). One study used a tool that had been validated in a different population but not in the in the diagnostic group reported (Vestala and Frisman, 2013). Sampling issues included unclear descriptions of randomisation (Vestala and Frisman, 2013) and non-independent data with repeated measures for some nurses (Florin et al., 2006). Small response rates reduced methodological quality (Florin et al., 2008, Florin et al., 2006).

\section{Meta-synthesis}

Three themes were discovered inductively in the data, which provided clarity on the way participation was enacted, the challenges facing participation and the way participation was promoted on medical wards. The final theme, types of participation, was found deductively.

\section{Enacting participation}

The theme enacting participation, described the variety of verbal and physical forms of participation in nursing care that were practiced on medical wards. Verbal participation activities studied included rounds, handovers, and information sharing encounters regarding treatment and disease. Decision-making with nurses was researched in a broad and sometimes an un-specified range of activities, relating to a variety of patient needs and nursing care. Some specific areas of patient participation in decision-making explored included documentation, medication administration and meals. Medication administration and hygiene were examined as aspects of physical participation.

\section{Challenges to participation}


The second theme, challenges to participation, illustrated that patient participation was hard to achieve, with many issues uncovered. Patients' capabilities were one factor that presented a challenge to achieving patient participation. In particular physical forms of participation, in the Iranian and Danish medical wards, seemed to be hindered by patients' capabilities and condition. The more unskilled and/or unwell the patient the less physical participation occurred.

Patient preferences were not fixed, presenting another challenge for patient participation. Participation in decision-making appeared to be influenced by preference rather than capabilities, with patients choosing to be active, collaborative or passive. On the whole, most patients admired roles where they were largely passive or collaborative with the nurses, rather than more active roles where choices were determined by the patient. Despite this, preferences for verbal participation did vary between contexts, with Swedish patients preferring more passive involvement, whereas, British and Australian patients chose a more active role.

While patients’ desire for patient participation could vary depending on their capability and preference, nurses tended to express a desire for a more patient-inclusive approach for all forms of patient participation. The incongruence between patient and nurse expectations for patient participation was apparent. Patients and nurses expectations and desires for patient participation were often not met and in some instances, patients reported undertaking more or less participation than wanted.

Patients' expectations were confounded by confusion on how patient participation should be enacted. Patients' perceptions revealed that some participation activities were viewed as the nurse's duty and patients were unsure of the level of participation they were expected to undertake. Some patients were not aware that decision-making was a nursing role, meaning patients could not foresee decision-making with nurses as an area in which 
they could participate. Overall, patients’ lack of clarity on enacting patient participation tended to entrench a passive approach.

A key challenge to effective patient participation was the manner of the nurse.

Patients’ confidence to participate was diminished when nurses displayed behaviours that were unsupportive of patient participation. Noticeably, when nurses appeared busy or taskorientated in nature, patient participation was difficult to achieve. Participation was also a challenge when nurses did not verbally engage, making patients feel uninformed or ignored, or when nurses did not show respectful communication towards patients; with condescending or de-personalised language being barriers.

Nurses’ manner towards communication meant some nurses failed to keep themselves informed. Both nurses and patients believed that nurses did not always know the patient when they came on shift. Nurses undertook activities without consulting patients and were not kept abreast of patients' willingness or expectations; this often placed nurses in an instructive and assuming role and, in some instances, nurses wrongly judged patients' willingness and expectations for patient participation. When nurses were viewed by patients as not attempting to understand their situation, patients simply complied with nurses or felt negative emotions such as fear and unhappiness. Overall, there were many patient and nurse related challenges to participation encountered on medical wards.

\section{Promoting participation}

Promoting participation, the third theme, portrays information-sharing as a facilitator to patient participation. Patients participated by gaining information from nurses, which made them feel included and informed. Patient participation in information sharing was characterised by patients asking questions, clarifying nurses' information or contributing to decision-making. Accordingly, patients appreciated their shared knowledge being respected by nursing staff. Information exchanges between patients and nurses were viewed by patients 
as a way of enhancing assessment of their capabilities and preferences and making nurse expectations explicit, with bedside handover viewed as a facilitator to information exchanges.

Vital to the success of involving patients in information sharing was the manner in which nurses portrayed themselves. When nurses displayed actions that were inviting, supporting and encouraging, patients’ eagerness to participate in information exchanges was enhanced. Further patient participation was boosted when nurses displayed respect through genuine engagement in dialogue, which was spoken in non-clinical language and acknowledging the patient as a person.

\section{Types of participation}

According to Soleimani et al.’s (2010) core category “convergence of the caring agents” there are four types of participation; adhering, involvement, sharing and true participation, each study was assessed to find the extent that these types of participation were found. Table three shows all but one study identified patients adhering to nurses' instruction rather than participation, with the majority of patients expressing a desire for adherent behaviour (Florin et al., 2008, Florin et al., 2006), or simply adhering to nurses regardless of their desire (Larsson et al., 2011, Lomborg and Kirkevold, 2008). Almost every study showed some elements of true partnerships with patients (Doherty and Doherty, 2005, Vestala and Frisman, 2013) and nurses (Florin et al., 2008, Lomborg and Kirkevold, 2008) expressing desires for patient involvement in decision-making, but this did not reflect how decisionmaking was (Lomborg and Kirkevold, 2008) or may have been practiced (Doherty and Doherty, 2005, Florin et al., 2006). Another feature of true participation encountered was patients sharing information that was valued by nurses (Larsson et al., 2011, McMurray et al., 2011). However, all elements of true partnership was only demonstrated in Soleimani et al.’s (2010) study, where patients were supported by nurses and used all their capabilities to take 
control of their care. Overall, adherent forms of participation were most easily achieved on medical wards.

Table 3 here

\section{Discussion}

The findings of this integrative review demonstrate that participation is commonly practiced in an adherent way on medical wards, which may be attributed to challenging and promoting factors. The challenges and promoters identified in our review resonate with Sahlsten et al.'s (2008) concept analysis. By discussing the challenges found in this review in relation to Sahlsten et al.’s (2008) four defining attributes, ways to improve patient participation in medical wards may be identified.

\section{Active mutual engagement in intellectual and/or physical activities}

Our review suggests that a challenge to participation was patients' willingness, which is required for achieving patient participation in intellectual or physical activities (Sahlsten et al., 2008). Willingness was influenced by patient preference and condition in this review. In terms of patient preference, the importance of nurses acknowledging desires for decisionmaking was highlighted and is a well-accepted factor in the success of shared decisionmaking (Coulter and Ellins, 2007, Longtin et al., 2010, Rise et al., 2013). Patients’ condition also influenced willingness to participate, as exemplified in Soleimani et al.’s (2010) study, with previous research also suggesting when patients are unwell their willingness to participate diminishes (Davis et al., 2007, Vaismoradi et al., 2014).

Given the variability of patient willingness, our review and Sahlsten et al.’s (2008) findings advocate the practice of nursing assessment prior to patient participation. Previous research indicates that nurses understand the value of involving patients in intentional assessments to achieve patient participation (Jewel, 1994, Sahlsten et al., 2005). Despite this 
recognition, this review suggests assessment of patient capability for patient participation is not easily operationalised or recognised in current medical ward nursing practice.

Questionnaire findings from Finnish nurses working in a geriatric hospital, implied only 56\% of nurses took patients’ assessment of their functional ability into account, with nurses tending to pursue family members' assessments rather than patients (Eloranta et al., 2014). Alarmingly, nurses reportedly practice assessment in a dominant and task-driven way, with little patient engagement (Barrere, 2007, Casey, 2007, Jones, 2009). Further complicating assessment, is a patient reluctance to share feelings of wellness (Huby et al., 2004). Ultimately, assessments with patients can improve communication and patient outcomes (Morse et al., 1996), and could be one strategy to overcome the challenges associated with patient willingness and reduce "adhering” practices of patient participation in medical wards.

Similar to Sahlsten et al. (2008), this review recommends undertaking care planning with patients, including discussion of goals. The planning process may help address conflicting expectations and role confusion found in this review. Discussing goals and expectations with patients has been identified by nurses as a strategy to promote patient participation (Sahlsten et al., 2009). Despite this, addressing patient goals and expectations appears to be challenging in other hospital settings, with only $20 \%$ of hospital nurses reporting they ask patient expectations (Rozenblum et al., 2011) and 52\% of hospital nurses ensured that patients knew the goal of their care (Eloranta et al., 2014). In hospital settings, plans are reportedly made away from patients (Wolf et al., 2012), or when patients do participate in planning nursing care it is a 'moderate' amount (Kolovos et al., 2014). Research suggests patients want to be part of the planning (Larsson et al., 2007, Rise et al., 2013), showing a thirst for participation. Planning with patients may be one method to promote more active patient participation on medical wards and achieve patient-centred care (Rathert et al., 2013); however, it needs to be catered to patients’ willingness. 


\section{An established relationship}

In our review it was evident that many nurses were perceived as 'busy' and often did not know or attempt to build a relationship with patients, an attribute necessary for successful patient participation (Sahlsten et al., 2008). Pressures on medical wards are common, created by frantic environments with high workloads and frequent staff rotation (Wolf et al., 2012). Working in a busy environment (Höglund et al., 2010, Penney and Wellard, 2007) and discontinuity of care (Larsson et al., 2011, Sahlsten et al., 2005) have been shown to impede co-operative relationships for participation in hospitals. In light of these pressures, our findings highlight the importance of the manner displayed by nurses. Nurses need to be aware that appearing task-orientated (Wellard et al., 2003) or bound by routine (Sahlsten et al., 2005) can thwart participatory relationships, as patients become adherent in an attempt not to disturb nurses (Foss, 2011). Ultimately, nurses need to engage and build relationships with patients to increase patient participation in medical wards; however, this is a true challenge due to pressures experienced in current hospital environments. Further research investigating ways to overcome these issues and enhance patient participation would be beneficial.

\section{A surrendering of some power and control by the nurse}

The high degree of adherence and numerous challenges discovered in this review suggests not all nurses were keen to surrender power, which is a pre-requisite for patient participation (Sahlsten et al., 2008). Controlling nurse manners identified in our review included being disrespectful or unengaging towards patients, thus impeding patient participation. Previous research strongly suggests that authoritative nurse behaviours such as these hinder patient participation (Aasen et al., 2012, Henderson, 2003), perhaps reflecting increases in the challenges and 'adhering' behaviour of patients found in our review. On the other hand, we found when nurses were respectful and encouraging, patient participation was 
promoted, especially in information-sharing. Previous studies conducted with patients (Larsson et al., 2007, Latimer et al., 2013) and nurses (Sahlsten et al., 2009) also identify supportive nurse manners as an enhancer of patient participation. In practice, medical ward nurses need to be aware of the effect their approach can have on patient participation.

\section{Shared information and knowledge}

Successful patient participation is characterised by shared information and knowledge (Sahlsten et al., 2008) which was an area of true participation more easily achieved by patients and nurses in this review. Patients (Eldh et al., 2006, Larsson et al., 2007) and nurses (Kolovos et al., 2014, Sahlsten et al., 2005) recognise the importance of information-sharing, viewing it as a condition for patient participation. Consistent with this review and previous

research, participation in information sharing can make patients feel respected (Rise et al., 2013) and involved (Lu et al., 2013). Other benefits of information-sharing include patient empowerment (Nygårdh et al., 2012) and enhanced knowledge, which is a contributor to enhanced patient participation (Davis et al., 2007, Vaismoradi et al., 2014), especially in decision-making (Joseph-Williams et al., 2014, Sainio et al., 2001). Interestingly, bedside handover was found to facilitate information-sharing in this review. Creating formal times for information-sharing, like bedside handover, can provide ease for patients to contribute (Chaboyer et al., 2008) and nurses to inform and update (Jeffs et al., 2014), which were communications valued in this review. Enacting information encounters like bedside handover may assist in achieving all attributes of patient participation, with improved assessment (Jeffs et al., 2014), planning (Kassean and Jagoo, 2004), knowledge of the patient (Chaboyer et al., 2010, Liu et al., 2012) and nurse (Anderson and Mangino, 2006, Wildner and Ferri, 2012), and greater patient empowerment (Lu et al., 2013) linked to bedside handover. 
This review contains several limitations. The inclusion of medical wards only may have restricted the findings; however, it provides a context-specific understanding of patient participation that will enhance transferability to similar clinical contexts. The researchers strategically designed and undertook a search strategy, specific to the aims of this study, yet there is always the possibility that some eligible articles may have been missed. This was an interpretive piece, which some may think results in a potential bias. But through the use of journaling ideas, feelings, and decisions, and frequent research team meetings, the researchers undertaking analysis attempted to stay true to the data and acknowledge biases. This study is also limited by the methodological quality of some articles included, however, limitations of the included studies have been acknowledged and made explicit through quality scores, allowing readers to take this into consideration. Overall, by following each step in Whittemore and Knafl's (2005) framework the rigour of this integrative review has been enhanced.

\section{Conclusion}

Although the benefits of patient participation are promising, patient participation is not easily achieved on medical wards. By overcoming various barriers, patients and nurses can potentially reap the benefits of active patient participation and create safety cultures in hospitals. This review illustrates information-sharing as a way to enhance patients' participation, which is one strategy to improve communication safety (Peat et al., 2010). Further, information sharing appears to benefit the patient by improving patient experience through making patients feel engaged, informed and respected. Information sharing was captured in two types of participation; "involvement in information sharing” and "true participation”. Achieving these types of participation that promote information sharing is valued by patients and can help foster the unique engagement that occurs between patient and nurse, allowing both to achieve nursing care together. 
There are implications for patient participation in practice, education and research to address the challenges encountered on medical wards. Patients should be encouraged to actively participate in assessment and care planning. Further, nurses may benefit from reflecting on their views on patient-centred care, and how these impact on patients' engagement (McCormack and McCance, 2006). Information-sharing activities, such as bedside handover, should be promoted on medical wards to enhance patient participation. Gaining a better understanding of the core attributes of patient participation may help nurses implement targeted strategies to promote participation. Further education for nurses on patient-centred approaches to care and interpersonal skills may be required to enhance patient participation on medical wards (McCormack and McCance, 2006). More research is needed to find ways to overcome barriers to patient participation. The research conducted in medical wards has been largely self-reported by patients, further research with nurses using observational data may help inform strategies to enhance patient participation. Thus, enhancing patient participation may be approached as a practice improvement, educational or research activity. 


\section{List of References}

Aasen, E.M., Kvangarsnes, M., Heggen, K., 2012. Perceptions of patient participation amongst elderly patients with end-stage renal disease in a dialysis unit. Scandinavian Journal of Caring Sciences 26 (1), 61-69. doi:10.1111/j.1471-6712.2011.00904.x

American Hospital Association (AHA), 2014. Resources: Strategies for leadership: Patient-and family-centered care, http://www.aha.org/advocacy-issues/quality/strategiespatientcentered.shtml (accessed 9.5.14).

Anderson, C.D., Mangino, R.R., 2006. Nurse shift report: Who says you can't talk in front of the patient? Nursing Administration Quarterly 30 (2), 112-122.

Australian Comission on Safety and Quality in Health Care (ACSQHC), 2011. Patient-centred care: Improving quality and safety through partnerships with patients and consumers. ACSQHC, Sydney, Australia.

Australian Comission on Safety and Quality in Health Care (ACSQHC), 2014. Resources to implement the NSQHS standards, http://www.safetyandquality.gov.au/ourwork/accreditation-and-the-nsqhs-standards/resources-to-implement-the-nsqhs-standards/\#top (accessed 9.5.14).

Barrere, C.C., 2007. Discourse analysis of nurse-patient communication in a hospital setting: Implications for staff development. Journal for Nurses in Staff Development 23 (3), 114-122. doi:10.1097/01.NND.0000277180.47829.8d

Berger, Z., Flickinger, T.E., Pfoh, E., Martinez, K.A., Dy, S.M., 2013. Promoting engagement by patients and families to reduce adverse events in acute care settings: A systematic review. BMJ Quality \& Safety 23 (7), 548-555. doi:10.1136/bmjqs-2012-001769

Bolster, D., Manias, E., 2010. Person-centred interactions between nurses and patients during medication activities in an acute hospital setting: Qualitative observation and interview study. International Journal of Nursing Studies 47 (2), 154-165. doi:10.1016/j.jpnurstu.2009.05.021

Cahill, J., 1998. Patient participation: A review of the literature. Journal Of Clinical Nursing 7 (2), 119-128. doi:10.1046/j.1365-2702.1998.00132.x 
Casey, D., 2007. Findings from non-participant observational data concerning health promoting nursing practice in the acute hospital setting focusing on generalist nurses. Journal Of Clinical Nursing 16 (3), 580-592. doi:10.1111/j.1365-2702.2006.01557.x

Chaboyer, W., McMurray, A., Wallis, M., 2010. Bedside nursing handover: A case study. International Journal of Nursing Practice 16 (1), 27-34. doi:10.1111/j.1440172X.2009.01809.X

Chaboyer, W., McMurray, A., Wallis, M., Chang, H.Y., 2008. Standard Operating Protocol for Implementing Bedside Handover in Nursing. Griffith University, Australia.

Cooke, A., Smith, D., Booth, A., 2012. Beyond PICO: The SPIDER tool for qualitative evidence synthesis. Qualitative Health Research 22 (10), 1435-1443. doi:10.1177/1049732312452938

Coulter, A., Ellins, J., 2007. Effectiveness of strategies for informing, educating, and involving patients. British Medical Journal 335 (7609), 24-27. doi:10.1136/bmj.39246.581169.80

D'Amour, D., Dubois, C.-A., Tchouaket, E., Clarke, S., Blais, R., 2014. The occurrence of adverse events potentially attributable to nursing care in medical units: Cross sectional record review. International Journal of Nursing Studies 51 (6), 882-891. doi:10.1016/j.ijnurstu.2013.10.017

Davis, R.E., Jacklin, R., Sevdalis, N., Vincent, C.A., 2007. Patient involvement in patient safety: What factors influence patient participation and engagement? Health Expectations 10 (3), 259-267. doi:10.1111/j.1369-7625.2007.00450.x

de Vries, E.N., Ramrattan, M.A., Smorenburg, S.M., Gouma, D.J., Boermeester, M.A., 2008. The incidence and nature of in-hospital adverse events: A systematic review. Quality \& Safety In Health Care 17 (3), 216-223. doi:10.1136/qshc.2007.023622

Doherty, C., Doherty, W., 2005. Patients' preferences for involvement in clinical decision-making within secondary care and the factors that influence their preferences. Journal of Nursing Management 13 (2), 119-127. doi:10.1111/j.1365-2934.2004.00498.x

Dudas, K., Olsson, L., Wolf, A., Swedberg, K., Taft, C., Schaufelberger, M., Ekman, I., 2013. Uncertainty in illness among patients with chronic heart failure is less in person-centred care than in usual care. European Journal of Cardiovascular Nursing 12 (6), 521-528. doi:10.1177/1474515112472270 
Dwamena, F., Holmes-Rovner, M., Gaulden, C.M., Jorgenson, S., Sadigh, G., Sikorskii, A., Lewin, S., Smith, R.C., Coffey, J., Olomu, A., 2012. Interventions for providers to promote a patientcentred approach in clinical consultations. The Cochrane Database of Systematic Reviews 12 (12), CD003267. doi:10.1002/14651858.CD003267.pub2.

Ekman, I., Wolf, A., Olsson, L., Taft, C., Dudas, K., Schaufelberger, M., Swedberg, K., 2012. Effects of person-centred care in patients with chronic heart failure: The PCC-HF study. European heart journal 33 (9), 1112-1119. doi:10.1093/eurheartj/ehr306

Eldh, A.C., Ekman, I., Ehnfors, M., 2010. A comparison of the concept of patient participation and patients' descriptions as related to healthcare definitions. International Journal of Nursing Terminologies and Classifications 21 (1), 21-32. doi:10.1111/j.1744-618X.2009.01141.x

Eldh, A.C., Ekman, I., Ehnfors, M., 2006. Conditions for patient participation and non-participation in health care. Nursing Ethics 13 (5), 503-514. doi:10.1191/0969733006nej898oa

Eloranta, S., Arve, S., Isoaho, H., Aro, I., Kalam-Salminen, L., Routasalod, P., 2014. Finnish nurses' perceptions of care of older patients. International Journal of Nursing Practice 20 (2), 204211. doi:10.1111/ijn.12137

Entwistle, V.A., 2000. Supporting and resourcing treatment decision-making: Some policy considerations. Health Expectations 3 (1), 77-85.

Florin, J., Ehrenberg, A., Ehnfors, M., 2008. Clinical decision-making: Predictors of patient participation in nursing care. Journal of Clinical Nursing 17 (21), 2935-2944. doi:10.1111/j.1365-2702.2008.02328.x

Florin, J., Ehrenberg, A., Ehnfors, M., 2006. Patient participation in clinical decision-making in nursing: A comparative study of nurses' and patients' perceptions. Journal of Clinical Nursing 15 (12), 1498-1508. doi:10.1111/j.1365-2702.2005.01464.x

Foss, C., 2011. Elders and patient participation revisited - A discourse analytic approach to older persons' reflections on patient participation. Journal Of Clinical Nursing 20 (13-14), 20142022. doi:10.1111/j.1365-2702.2010.03505.x

Gallivan, J., Kovacs Burns, K., Bellows, M., Eigenseher, C., 2012. The many faces of patient engagement. Journal of Participatory Medicine 4, e32. 
Hall, J., Peat, M., Birks, Y., Golder, S., Entwistle, V., Gilbody, S., Mansell, P., McCaughan, D., Sheldon, T., Watt, I., Williams, B., Wright, J., 2010. Effectiveness of interventions designed to promote patient involvement to enhance safety: A systematic review. Quality \& Safety in Health Care 19 (5), e10. doi:10.1136/qshc.2009.032748

Henderson, S., 2003. Power imbalance between nurses and patients: A potential inhibitor of partnership in care. Journal Of Clinical Nursing 12 (4), 501-508. doi:10.1046/j.13652702.2003.00757.x

Huby, G., Stewart, J., Tierney, A., Rogers, W., 2004. Planning older people's discharge from acute hospital care: Linking risk management and patient participation in decision-making. Health, Risk \& Society 6 (2), 115-132. doi:10.1080/1369857042000219797

Höglund, A.T., Winblad, U., Arnetz, B., Arnetz, J.E., 2010. Patient participation during hospitalization for myocardial infarction: Perceptions among patients and personnel. Scandinavian Journal of Caring Sciences 24 (3), 482-489. doi:10.1111/j.14716712.2009.00738.x

Jeffs, L., Beswick, S., Acott, A., Simpson, E., Cardoso, R., Campbell, H., Irwin, T., 2014. Patients' views on bedside nursing handover: Creating a space to connect. Journal of Nursing Care Quality 29 (2), 149-154. doi:10.1097/NCQ.0000000000000035

Jewel, S.E., 1994. Patient participation: What does it mean to nurses? Journal of Advanced Nursing 19 (3), 433-438. doi:10.1111/j.1365-2648.1994.tb01104.x

Jones, A., 2009. Creating history: Documents and patient participation in nurse-patient interviews. Sociology of Health \& Illness 31 (6), 907-923. doi:10.1111/j.1467-9566.2009.01190.x

Joseph-Williams, N., Elwyn, G., Edwards, A., 2014. Knowledge is not power for patients: A systematic review and thematic synthesis of patient-reported barriers and facilitators to shared decision making. Patient Education and Counseling 94 (3), 291-309.

doi:10.1016/j.pec.2013.10.031

Kassean, H.K., Jagoo, Z.B., 2004. Managing change in the nursing handover from traditional to bedside handover - A case study from Mauritius. BioMed Central Nursing 4 (1). doi:10.1186/1472-6955-4-1 
Kitson, A., Marshall, A., Bassett, K., Zeitz, K., 2013. What are the core elements of patient-centred care? A narrative review and synthesis of the literature from health policy, medicine and nursing. Journal of Advanced Nursing 69 (1), 4-15. doi:10.1111/j.1365-2648.2012.06064.x

Kolovos, P., Kaitelidou, D., Lemonidou, C., Sachlas, A., Sourtzi, P., 2014. Patient participation in decision making during nursing care in Greece - A comparative study. Nursing Forum. Advance online publication. doi:10.1111/nuf.12089

Kolovos, P., Kaitelidou, D., Lemonidou, C., Sachlas, A., Zyga, S., Sourtzi, P., 2014. Patient participation in hospital care: Nursing staffs' point of view. International Journal of Nursing Practice. Advance online publication. doi:10.1111/ijn.12242

Koutantji, M., Davis, R., Vincent, C., Coulter, A., 2005. The patient's role in patient safety: Engaging patients, their representatives, and health professionals. Clinical Risk 11 (3), 99-104.

Langton, H., Barnes, M., Haslehurst, S., Rimmer, J., Turton, P., 2003. Collaboration, user involvement and education: A systematic review of the literature and report of an educational initiative. European Journal of Oncology Nursing 7 (4), 242-252. doi:10.1016/S14623889(03)00033-4

Larsson, I.E., Sahlsten, M.J.M., Segesten, K., Plos, K.A.E., 2011. Patients' perceptions of nurses' behaviour that influence patient participation in nursing care: A critical incident study. Nursing Research and Practice 2011. doi:10.1155/2011/534060

Larsson, I.E., Sahlsten, M.J.M., Segesten, K., Plos, K.A.E., 2011. Patients’ perceptions of barriers for participation in nursing care. Scandinavian Journal of Caring Sciences 25 (3), 575-582. doi:10.1111/j.1471-6712.2010.00866.x

Larsson, I.E., Sahlsten, M.J.M., Sjöström, B., Lindencrona, C.S.C., Plos, K.A.E., 2007. Patient participation in nursing care from a patient perspective: A grounded theory study. Scandinavian Journal of Caring Sciences 21 (3), 313-320. doi:10.1111/j.14716712.2007.00471.x

Latimer, S., Chaboyer, W., Gillespie, B., 2013. Patient participation in pressure injury prevention: Giving patient's a voice. Scandinavian Journal of Caring Sciences 28 (4), 648-656. doi:10.1111/scs.12088 
Liu, W., Manias, E., Gerdtz, M., 2012. Medication communication between nurses and patients during nursing handovers on medical wards: A critical ethnographic study. International Journal of Nursing Studies 49 (8), 941-952. doi:10.1016/j.ijnurstu.2012.02.008

Lomborg, K., Kirkevold, M., 2008. Achieving therapeutic clarity in assisted personal body care: Professional challenges in interactions with severely ill COPD patients. Journal Of Clinical Nursing 17 (16), 2155-2163. doi:10.1111/j.1365-2702.2006.01710.x

Longtin, Y., Sax, H., Leape, L.L., Sheridan, S.E., Donaldson, L., Pittet, D., 2010. Patient participation: Current knowledge and applicability to patient safety. Mayo Clinic Proceedings 85 (1), 53-62. doi:10.4065/mcp.2009.0248

Lu, S., Kerr, D., McKinlay, L., 2013. Bedside nursing handover: Patients' opinions. International Journal of Nursing Practice 20 (5), 451-459. doi:10.1111/ijn.12158

McCormack, B., McCance, T.V., 2006. Development of a framework for person-centred nursing. Journal of Advanced Nursing 56 (5), 472-479. doi:10.1111/j.1365-2648.2006.04042.x

McMurray, A., Chaboyer, W., Wallis, M., Johnson, J., Gehrke, T., 2011. Patients’ perspectives of bedside nursing handover. Collegian 18 (1), 19-26. doi:10.1016/j.colegn.2010.04.004

National Institute for Health and Care Excellence (NICE), 2012. Quality standard for patient experience in adult NHS services http://publications.nice.org.uk/quality-standard-for-patientexperience-in-adult-nhs-services-qs15 (accessed 9.5.14).

Nygårdh, A., Malm, D., Wikby, K., Ahlström, G., 2012. The experience of empowerment in the patient-staff encounter: The patient's perspective. Journal Of Clinical Nursing 21 (5-6), 897 904. doi:10.1111/j.1365-2702.2011.03901.x

Pace, R., Pluye, P., Bartlett, G., Macaulay, A., Salsberg, J., Jagosh, J., Seller, R., 2010. Reliability of a tool for concomitantly appraising the methodological quality of qualitative, quantitative and mixed methods research: A pilot study. 38th Annual Meeting of the North American Primary Care Research Group (NAPCRG), Seattle, USA., http://mixedmethodsappraisaltoolpublic.pbworks.com/f/Pace-Pluye-et-al-final-poster-201010-29.pdf (accessed 2.8.13). 
Pace, R., Pluye, P., Bartlett, G., Macaulay, A., Salsberg, J., Jagosh, J., Seller, R., 2012. Testing the reliability and efficiency of the pilot Mixed Methods Appraisal Tool (MMAT) for systematic mixed studies review. International Journal of Nursing Studies 49 (1), 47-53. doi:10.1016/j.ijnurstu.2011.07.002

Pearson, A., 2004. Balancing the evidence: Incorporating the synthesis of qualitative data into systematic reviews. JBI Reports 2 (2), 45-64. doi:10.1111/j.1479-6988.2004.00008.x

Peat, M., Entwistle, V., Hall, J., Birks, Y., Golder, S., 2010. Scoping review and approach to appraisal of interventions intended to involve patients in patient safety. Journal of Health Services Research \& Policy 15 (1), 17-25. doi:10.1258/jhsrp.2009.009040

Penney, W., Wellard, S.J., 2007. Hearing what older consumers say about participation in their care. International Journal of Nursing Practice 13 (1), 61-68. doi:10.1111/j.1440172X.2006.00608.X

Pluye, P., Gagnon, M.P., Griffiths, F., Johnson-Lafleur, J., 2009. A scoring system for appraising mixed methods research, and concomitantly appraising qualitative, quantitative and mixed methods primary studies in mixed studies reviews. International Journal of Nursing Studies 46 (4), 529-546. doi:10.1016/j.jinurstu.2009.01.009

Pluye, P., Robert, E., Cargo, M., Bartlett, G., O'Cathain, A., Griffiths, F., Boardman, F., Gagnon, M.P., Rousseau, M.C., 2011. Proposal: A mixed methods appraisal tool for systematic mixed studies reviews, http://mixedmethodsappraisaltoolpublic.pbworks.com (accessed 1.8.13).

Polit, D.F., Beck, C.T., 2008. Nursing research: Generating and assessing evidence for nursing practice Lippincott Williams \& Wilkins, Philadelphia, Pennsylvania.

Rathert, C., Wyrwich, M.D., Boren, S.A., 2013. Patient-centered care and outcomes: A systematic review of the literature. Medical Care Research and Review 70 (4), 351-379. doi:10.1177/1077558712465774

Rise, M.B., Solbjør, M., Lara, M.C., Westerlund, H., Grimstad, H., Steinsbekk, A., 2013. Same description, different values. How service users and providers define patient and public involvement in health care. Health Expectations 16 (3), 266-276. doi:10.1111/j.13697625.2011.00713.x 
Rozenblum, R., Lisby, M., Hockey, P.M., Levtizion-Korach, O., Salzberg, C.A., Lipsitz, S., Bates, D.W., 2011. Uncovering the blind spot of patient satisfaction: An international survey. BMJ Quality and Safety 20 (11), 959-965. doi:10.1136/bmjqs-2011-000306

Sahlsten, M.J.M., Larsson, I.E., Lindencrona, C.S.C., Plos, K.A.E., 2005. Patient participation in nursing care: An interpretation by Swedish registered nurses. Journal Of Clinical Nursing 14 (1), 35-42. doi:10.1111/j.1365-2702.2004.00957.x

Sahlsten, M.J.M., Larsson, I.E., Plos, K.A.E., Lindencrona, C.S.C., 2005. Hindrance for patient participation in nursing care. Scandinavian Journal of Caring Sciences 19 (3), 223-229. doi:10.1111/j.1471-6712.2005.00336.x

Sahlsten, M.J.M., Larsson, I.E., Sjöström, B., Plos, K.A.E., 2008. An analysis of the concept of patient participation. Nursing Forum 43 (1), 2-11. doi:10.1111/j.1744-6198.2008.00090.x

Sahlsten, M.J.M., Larsson, I.E., Sjöström, B., Plos, K.A.E., 2009. Nurse strategies for optimising patient participation in nursing care. Scandinavian Journal of Caring Sciences 23 (3), 490497. doi:10.1111/j.1471-6712.2008.00649.x

Sainio, C., Lauri, S., Eriksson, E., 2001. Cancer patients' views and experiences of participation in care and decision making. Nursing Ethics 8 (2), 97-113. doi:10.1191/096973301677733388

Sandelowski, M., Voils, C.I., Barroso, J., 2006. Defining and designing mixed research synthesis studies. Research in the Schools 13 (1), 29-44.

Schwappach, D., 2010. Review: Engaging patients as vigilant partners in safety: A systematic review. Medical Care Research and Review 67 (2), 119-148. doi:10.1177/1077558709342254

Slatore, C.G., 2010. Patient-clinician communication: Associations with important health outcomes among veterans with COPD. Chest 138 (3), 628-634. doi:10.1378/chest.09-2328

Soleimani, M., Rafii, F., Seyedfatemi, N., 2010. Participation of patients with chronic illness in nursing care: An Iranian perspective. Nursing \& Health Sciences 12 (3), 345-351. doi:10.1111/j.1442-2018.2010.00536.x

Sørensen, D., Frederiksen, K., Groefte, T., Lomborg, K., 2013. Nurse-patient collaboration: A grounded theory study of patients with chronic obstructive pulmonary disease on non- 
invasive ventilation. International Journal of Nursing Studies 50 (1), 26-33.

doi:10.1016/j.ijnurstu.2012.08.013

Thomas, J., Harden, A., 2008. Methods for the thematic synthesis of qualitative research in systematic reviews. BioMed Central medical research methodology 8 (1), 45-45. doi:10.1186/14712288-8-45

University of Gothenburg Centre for Person-centred Care (GPCC), 2014. Person-centred care, http://gpcc.gu.se/digitalAssets/1477/1477256_eng-broschyr_gpcc_147x147_web.pdf (accessed 11.12.14).

Vaismoradi, M., Jordan, S., Kangasniemi, M., 2014. Patient participation in patient safety and nursing input - A systematic review. Journal Of Clinical Nursing. Advance online publication. doi:10.1111/jocn.12664

Vestala, H., Frisman, G.H., 2013. Can participation in documentation influence experiences of involvement in care decision-making? The Open Nursing Journal 7 (1), 66-72. doi:10.2174/1874434620130516002

Voils, C.I., Sandelowski, M., Barroso, J., Hasselblad, V., 2008. Making sense of qualitative and quantitative findings in mixed research synthesis studies. Field Methods 20 (1), 3-25. doi:10.1177/1525822x07307463

Weingart, S.N., Zhu, J., Chiappetta, L., Stuver, S.O., Schneider, E.C., Epstein, A.M., David-Kasdan, J.A., Annas, C.L., Fowler, F.J., Jr., Weissman, J.S., 2011. Hospitalized patients' participation and its impact on quality of care and patient safety. International Journal for Quality in Health Care 23 (3), 269-277. doi:10.1093/intqhc/mzr002

Wellard, S., Lillibridge, J., Beanland, C., Lewis, M., 2003. Consumer participation in acute care settings: an Australian experience. International Journal of Nursing Practice 9 (4), 255-260. doi:10.1046/j.1440-172X.2003.00429.x

Whittemore, R., Knafl, K., 2005. The integrative review: Updated methodology. Journal of Advanced Nursing 52 (5), 546-553. doi:10.1111/j.1365-2648.2005.03621.x 
Wildner, J., Ferri, P., 2012. Patient participation in change-of-shift procedures: The implementation of the bedside handover for the improvement of nursing quality in an Italian hospice. Journal of Hospice and Palliative Nursing 14 (3), 216-224. doi:10.1097/NJH.0b013e318243251f

Wolf, A., Ekman, I., Dellenborg, L., 2012. Everyday practices at the medical ward: A 16-month ethnographic field study. BioMed Central Health Services Research 12 (1), 184-196. doi:10.1186/1472-6963-12-184 
Tables

Table 1

First Search Strategy Utilised via Computerised Databases

\begin{tabular}{|c|c|c|c|c|}
\hline Steps & $\begin{array}{l}\text { CINAHL } \\
\text { (CINAHL } \\
\text { headings) }\end{array}$ & $\begin{array}{l}\text { Cochrane Library } \\
\text { (MeSH terms) }\end{array}$ & $\begin{array}{l}\text { Medline } \\
\text { (MeSH terms) }\end{array}$ & $\begin{array}{l}\text { PsycINFO } \\
\text { (Subject } \\
\text { headings) }\end{array}$ \\
\hline S1 & $\begin{array}{l}\text { (MH } \\
\text { "Consumer } \\
\text { Participation") }\end{array}$ & $\begin{array}{l}\text { (MH "Cooperative } \\
\text { Behavior") OR (MH } \\
\text { "Consumer } \\
\text { Participation") OR } \\
\text { (MH "Patient } \\
\text { Participation") }\end{array}$ & $\begin{array}{l}\text { (MH "Cooperative } \\
\text { Behavior") OR } \\
\text { (MH "Consumer } \\
\text { Participation+") }\end{array}$ & $\begin{array}{l}\text { exp Client } \\
\text { Participation/ }\end{array}$ \\
\hline S2 & $\begin{array}{l}\text { (MH "Nurses") } \\
\text { OR (MH "Staff } \\
\text { Nurses") OR } \\
\text { (MH "Nursing } \\
\text { Staff, } \\
\text { Hospital") OR } \\
\text { (MH } \\
\text { "Patients") OR } \\
\text { (MH } \\
\text { "Inpatients") }\end{array}$ & $\begin{array}{l}\text { (MH "Nurses/PX") } \\
\text { OR (MH "Nursing } \\
\text { Staff+/PX") OR } \\
\text { (MH Nursing Staff, } \\
\text { Hospital+/PX") OR } \\
\text { (MH "Patients/PX") } \\
\text { OR (MH } \\
\text { "Inpatients/PX") }\end{array}$ & $\begin{array}{l}\text { (MH } \\
\text { "Nurses/PX") OR } \\
\text { (MH "Nursing } \\
\text { Staff+/PX") OR } \\
\text { (MH } \\
\text { "Patients/PX") OR } \\
\text { (MH } \\
\text { "Inpatients/PX") }\end{array}$ & $\begin{array}{l}\text { hospitalized } \\
\text { patients/ or } \\
\text { exp patients/ } \\
\text { or nurses/ }\end{array}$ \\
\hline S3 & S1 AND S2 & S1 AND S2 & S1 AND S2 & S1 AND S2 \\
\hline S4 & $\begin{array}{l}\text { Limiters: Date } \\
\text { of Publication: } \\
\text { 1999-2013; } \\
\text { English } \\
\text { Language. } \\
\text { Narrow by } \\
\text { subject age: all } \\
\text { adult }\end{array}$ & $\begin{array}{l}\text { Limiters: Date of } \\
\text { Publication: 1999- } \\
2013\end{array}$ & $\begin{array}{l}\text { Limiters: Date of } \\
\text { Publication: 1999- } \\
\text { 2013; English } \\
\text { Language. Narrow } \\
\text { by subject age: all } \\
\text { adult: 19+ years }\end{array}$ & $\begin{array}{l}\text { Limiters: Date } \\
\text { of Publication: } \\
\text { 1999-current; } \\
\text { English } \\
\text { Language. } \\
\text { Narrow by } \\
\text { subject age: } \\
\text { [300] } \\
\text { adulthood } \\
\text { (age } 18 \text { yrs } \\
\text { and older) }\end{array}$ \\
\hline
\end{tabular}




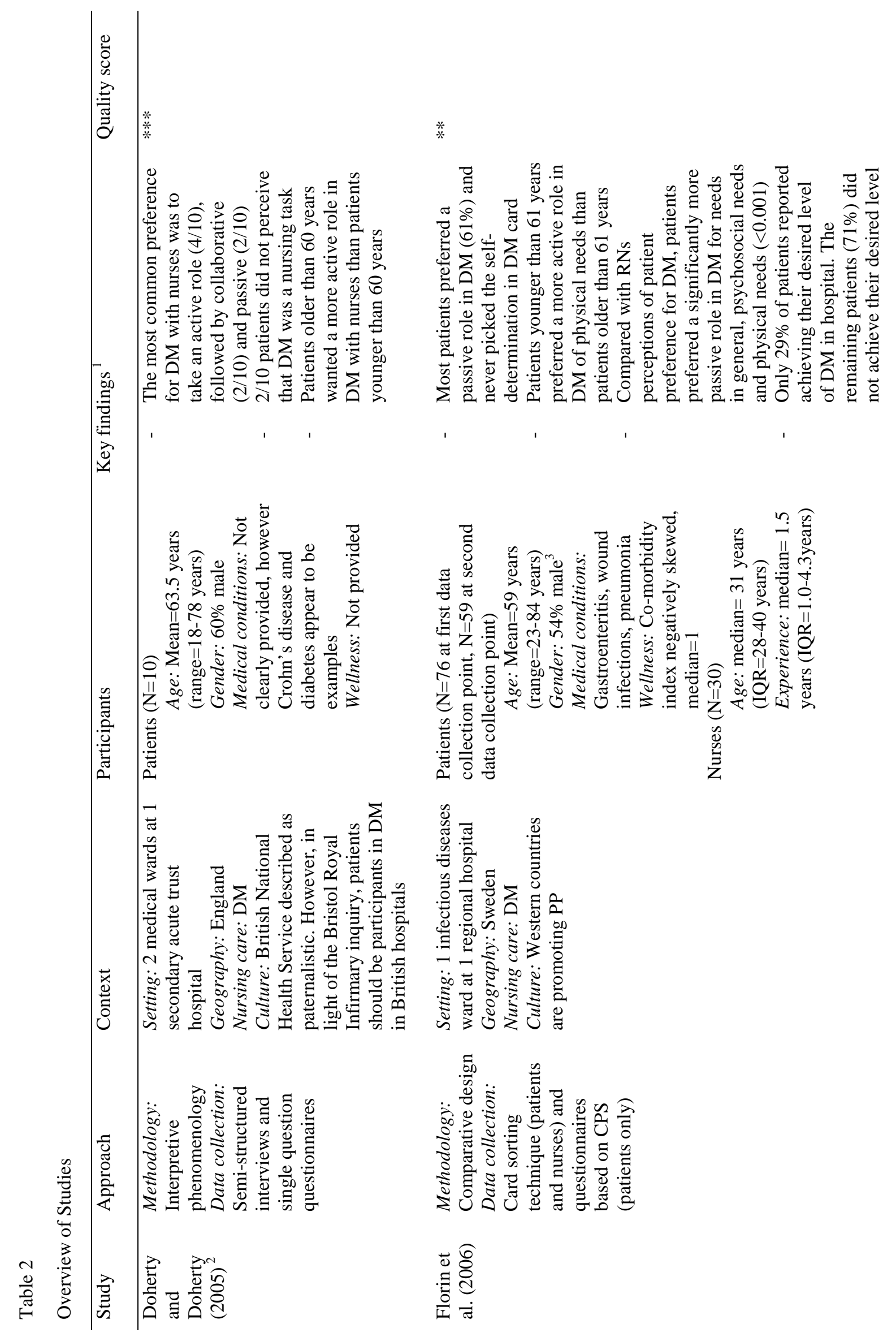




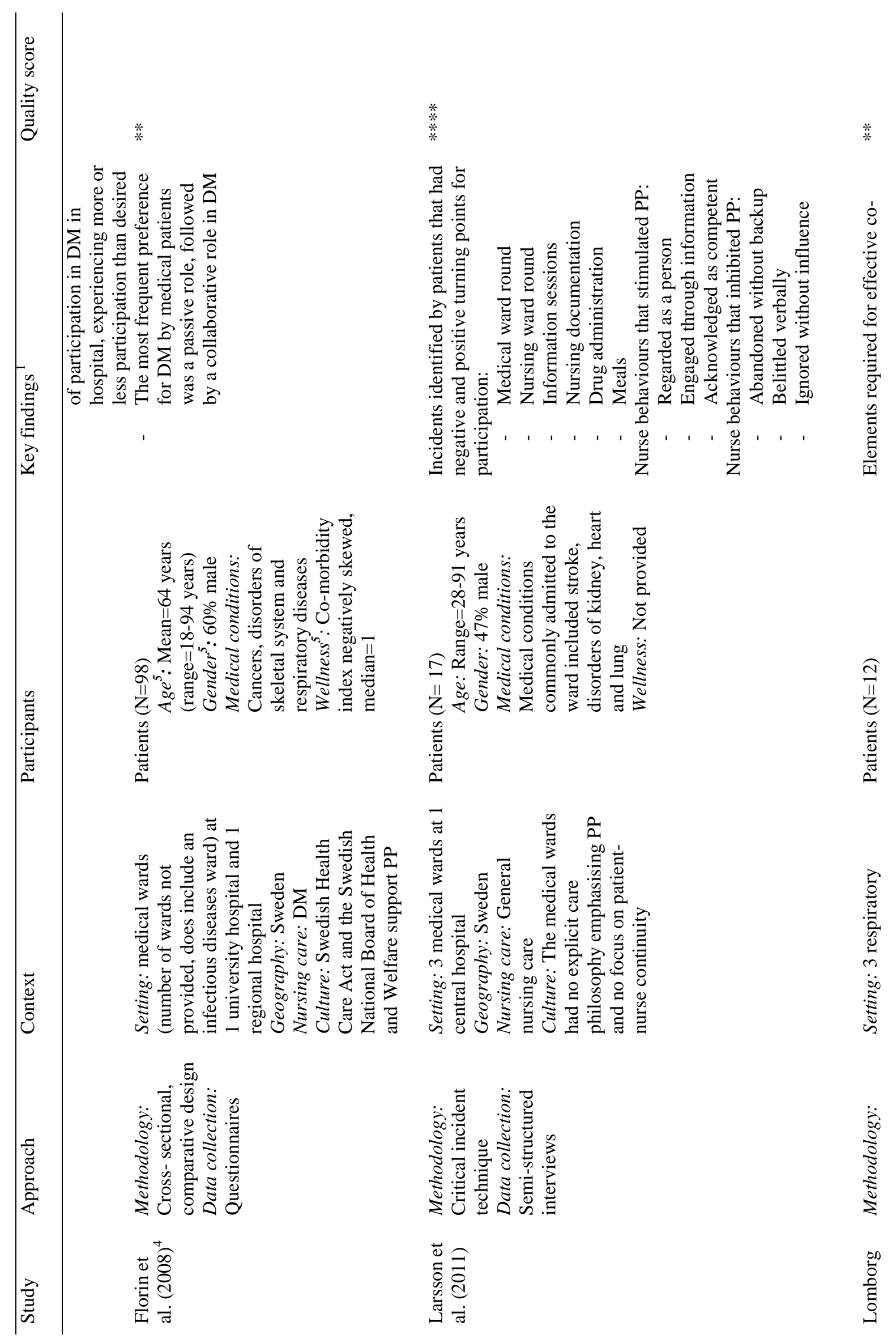




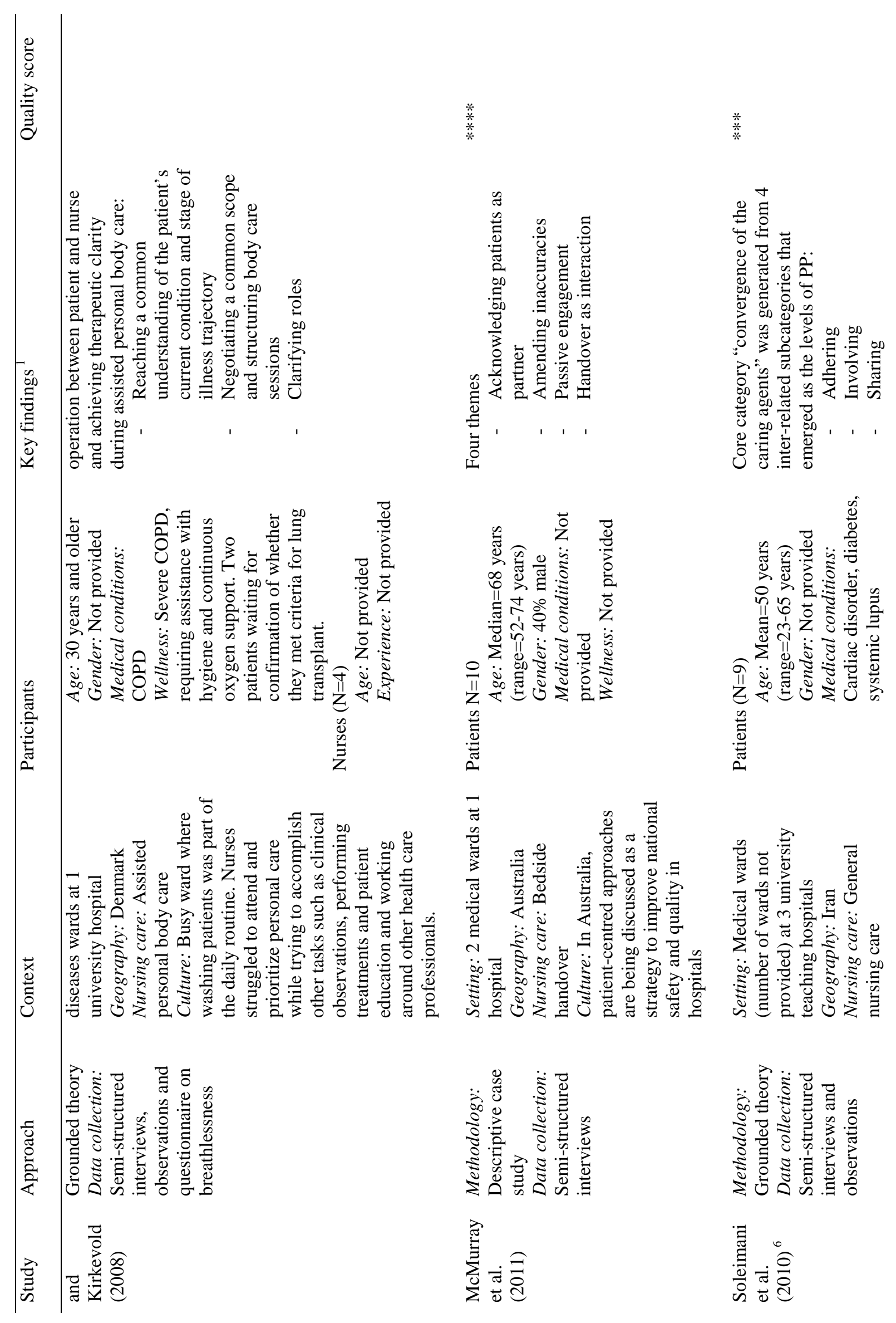




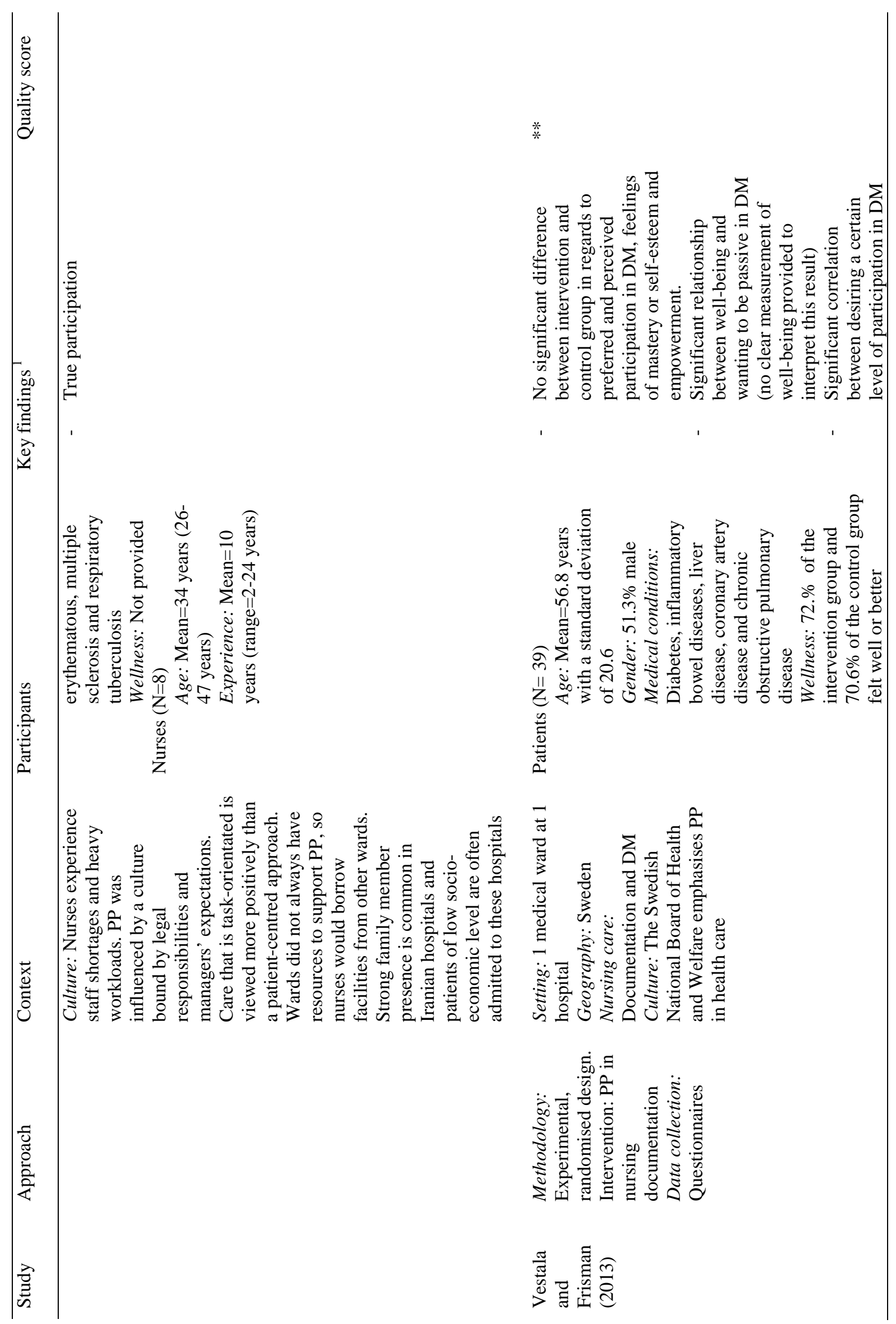




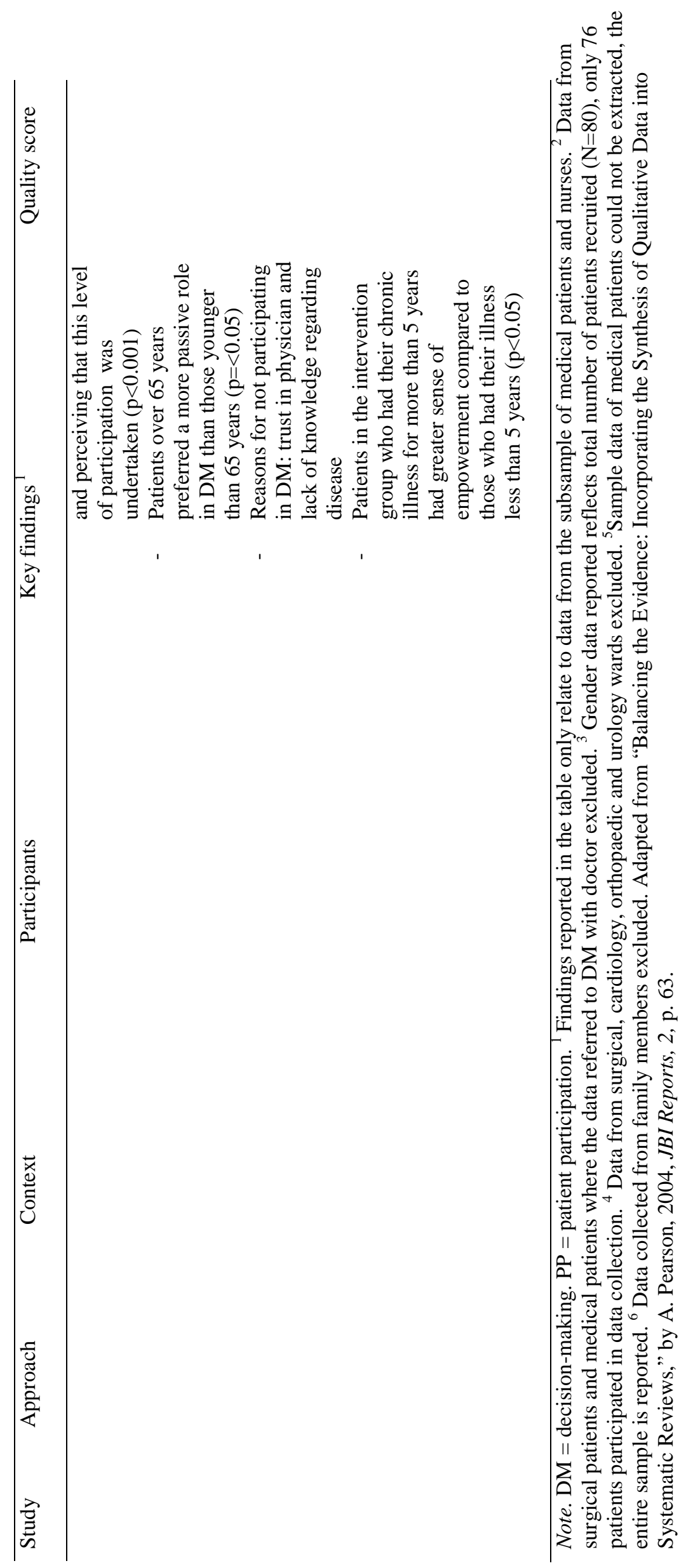


Table 3

Types of Participation Assessed with Soleimani et al.’s (2010) Grounded Theory Category “Convergence of the Caring Agents”

\begin{tabular}{lcccc}
\hline Author/Year & $\begin{array}{c}\text { Adhering } \\
\text { to nurse } \\
\text { instructions }\end{array}$ & $\begin{array}{c}\text { Involvement } \\
\text { through } \\
\text { informing } \\
\text { patients }\end{array}$ & $\begin{array}{c}\text { Sharing } \\
\text { physical } \\
\text { activities }\end{array}$ & $\begin{array}{c}\text { True } \\
\text { partnership } \\
\text { between } \\
\text { patient and } \\
\text { nurse }\end{array}$ \\
\hline $\begin{array}{l}\text { Doherty and } \\
\text { Doherty (2005) } \\
\text { Florin et al. (2006) }\end{array}$ & $\mathrm{P}$ & - & - & $\mathrm{P} *$ \\
$\begin{array}{l}\text { Florin et al. (2008) } \\
\text { Larsson et al. }\end{array}$ & $\mathrm{P}$ & - & - & $\mathrm{N} *$ \\
$\begin{array}{l}\text { (2011) } \\
\text { Lomborg and }\end{array}$ & $\mathrm{P}$ & $\mathrm{P}$ & - & - \\
$\begin{array}{l}\text { Kirkevold (2008) } \\
\text { McMurray et al. }\end{array}$ & $\mathrm{P} / \mathrm{N}$ & $\mathrm{N}$ & $\mathrm{N}$ & $\mathrm{P} *$ \\
$\begin{array}{l}\text { (2011) } \\
\text { Soleimani et al. } \\
\text { (2010) }\end{array}$ & $\mathrm{P}$ & $\mathrm{P}$ & - & $\mathrm{P} *$ \\
$\begin{array}{l}\text { Vestala and } \\
\text { Frisman (2013) }\end{array}$ & $\mathrm{P}$ & $\mathrm{P} / \mathrm{N}$ & $\mathrm{P} / \mathrm{N}$ & $\mathrm{P} / \mathrm{N}$ \\
\hline
\end{tabular}

Note. Participation desired, perceived or enacted by patient (P), participation desired, perceived or enacted by nurse $(\mathrm{N})$. Only some elements of "true participation" were desired, perceived or enacted (*).Adapted from "Participation of Patients with Chronic Illness in Nursing Care: An Iranian Perspective,” by M. Soleimani, F. Rafii, and N. Seyedfatemi, 2010, Nursing and Health Sciences, 12, p. 347 